\title{
Timing of Carotid Endarterectomy: Perioperative Outcome According to Index Event to Operation Room Time
}

\author{
Mehmet Kalender ${ }^{1 *}$, Ahmet Nihat Baysal' ${ }^{1}$, Ata Niyazi Ecevit ${ }^{1}$, \\ Okay Güven Karaca ${ }^{2}$, Mehmet Tasar ${ }^{3}$, Salih Salihi ${ }^{4}$ \\ ${ }^{1}$ Cardiovascular Surgery Department, Konya Education and Research Hospital, Konya, Turkey \\ ${ }^{2}$ Cardiovascular Surgery Department, Duzce University Medical School Hospital, Duzce, Turkey \\ ${ }^{3}$ Surgery Department, Ankara University Medical School Hospital, Ankara, Turkey \\ ${ }^{4}$ Cardiovascular Surgery Department, Nigde State Hospital, Nigde, Turkey \\ Email: ka97084@yahoo.com
}

Received 2 August 2014; revised 1 September 2014; accepted 29 September 2014

Copyright (C) 2014 by authors and Scientific Research Publishing Inc.

This work is licensed under the Creative Commons Attribution International License (CC BY). http://creativecommons.org/licenses/by/4.0/

(c) () D Den Access

\begin{abstract}
Aim: Carotid endarterectomy (CEA) is the choice of treatment for prevention of cerebrovascular events in vulnerable patients. In this single-center multi surgeon study, we aimed to evaluate outcomes of neurologically stable patients who underwent CEA after symptoms of cerebrovascular event according to time between the event and operation. Methods: In our clinic during 2008-2012, we applied 67 CEA to 65 patients. Ten of these 65 patients excluded from trial due to combined CABG operation. 18 patients were asymptomatic prior to operation and excluded. Thirty-nine of these patients were symptomatic and enrolled to study. Data were collected retrospectively. All enrolled patients were divided into two groups, according to the time between event and operation. Group I: Early Group ( $\leq 14$ days). Group II: Late Group ( $>14$ days). Results: In our clinic during 2008-2012, we applied 39 CEA procedures to consecutive 37 patients with symptomatic carotid artery stenosis. None of preoperative variables were associated with postoperative mortality ( $p>0.05)$. We observed postoperative bleeding in one patient who was in Late Group (II). Postoperative bleeding was only associated with hyperlipidemia $(p=0.003)$. Postoperative stroke was observed in moderate cardiac risk patients in Early Group (I) $(p=0.003)$. But none of the postoperative complications were associated with study groups. We observed that, closure technique (primary closure) was associated with postoperative stroke $(p=0.030)$. We have achieved shorter waiting time during study time phrase but it couldn't reached statistical significance $(p=$ 0.196). Conclusion: Although symptomatic patients have a higher risk of perioperative complications compared with asymptomatic patients, early CEA after symptom onset does not influence the results. This raises the question of the optimal timing of Carotid Artery intervention in sympto"Corresponding author.
\end{abstract}


matic carotid artery stenosis. To answer this question, more data are needed preferably from large randomized trials.

\title{
Keywords
}

\author{
Cerebrovascular Event, Carotid Artery Stenosis, Endarterectomy
}

\section{Introduction}

Carotid endarterectomy (CEA) is the choice of treatment for prevention of cerebrovascular events in vulnerable patients. European guidelines recommend revascularization within 2 weeks of index event (first symptom described by the patient) in patient with symptomatic carotid artery stenosis [1]-[5]. In several vascular centers including our clinic, shorter waiting times have been achieved over the last few years, but the majority of patients are still not treated within the recommended 2 weeks from symptoms [6]-[8].

Up to date, guidelines suggest early revascularization [4] but previously reported papers advocate late revascularization due to risk of non-hemorrhagic infarct transition into a hemorrhagic one and consequent extension of the infarcted area [9]. Rantner et al. demonstrated no difference in major complication rates among 29 CEAs performed before and 62 CEAs performed after 28 days from symptoms. Faggioli et al. reported no statistical difference of perioperative stroke rate according to operation time.

In this present single-center multi surgeon study, we aimed to evaluate outcomes of neurologically stable patients who underwent CEA after symptoms of cerebrovascular event according to time between event and operation.

\section{Patients and Method}

In our clinic during 2008-2012, we applied 67 CEAs to 65 patients. 10 of these 65 patients were excluded from trial due to combined Coronary Artery Bypass Grafting (CABG) operation. 18 patients were asymptomatic prior to operation and excluded. Thirty-seven of these patients (two patients had bilateral carotid endarterectomy) were symptomatic and enrolled to study. Data were collected retrospectively. Patients had either deep or superficial cervical plexus block anesthesia which was decided by anesthesiology, none needed to switch general anesthesia. Bupivacaine and lidocaine were used as anesthetic agents. Shunt was used in the absence of sufficientback flow to the internal carotid artery, or severe stenosis in contra lateral carotid artery or in patients with neurological deficits observed after clamping during the operation. Carotid arteriotomy was closed either primary or by using a patch. One of saphenousvein, Dacron, fabric or carotid patch was used. Postoperative all patients had standard medication dictated by guidelines such as antithrombotic, antiplatelet, statin, antihypertensive-if needed-, and antibiotic.

All enrolled patients were divided into two groups, according to the time between event and operation.

Group I: Early Group ( $\leq 14$ days).

Group II: Late Group ( $>14$ days).

\section{Statistical Analysis}

Statistical analysis was performed using the Statistical Package for Social Sciences (SPSS) 15.0 software (SPSS Inc. Chicago, IL, USA). Categorical data were expressed as percentages and continuous variables as mean with standard deviation. Possible significant differences were analyzed between the groups by means of the chisquared test and Fischer's exact test. A p value $<0.05$ was defined as statistically significant, thus adjusting for the fact that multiple analyses were performed.

\section{Results}

In our clinic during 2008-2012, we applied 39 CEAs to consecutive 37 patients with symptomatic carotid artery stenosis. Mean age of patients was $67.79 \pm 10.19$ (range 41 - 85). 15 (26.31\%) of patients were female. Late group patients had more severe lesion but the difference did not reached statistical significance. Baseline patient 
characteristics had no significant differences among groups (Table 1). In both groups major symptom was dizziness but patients' symptoms were not statistically different among groups $(\mathrm{p}>0.05)$ (Table 2). None of preoperative variables were associated with postoperative mortality $(p>0.05)$. We observed postoperative bleeding in one patient who was in Late Group (II). Postoperative bleeding was only associated with hyperlipidemia $(\mathrm{p}=0.003)$. Postoperative stroke was observed in moderate cardiac risk patients both were in Early Group (I) $(\mathrm{p}=0.003)$ but none of the postoperative complications were associated with study groups (Table 3$)$. We observed that, closure technique (primary closure) was associated with postoperative stroke $(p=0.030)$. We have achieved shorter waiting time during study time phrase (particularly last year) but it couldn't reached statistical significance $(\mathrm{p}=0.196)$ (Figure 1$)$ (Table 4).

Table 1. Demographic variables of patients.

\begin{tabular}{|c|c|c|c|}
\hline Demographic Characteristics & Group I (early) $(\mathrm{n}=15)$ & Group II (late) (n = 24) & $\mathrm{p}$ \\
\hline Mean Age, yr (SD) & $68.27 \pm 10.0$ & $68.0 \pm 10.70$ & \\
\hline Male & 9 & 19 & 0.196 \\
\hline Hypertension & 8 & 12 & 0.55 \\
\hline Diabetes & 5 & 5 & 0.384 \\
\hline COPD & 4 & 4 & 0.686 \\
\hline Hyperlipidemia & 2 & 2 & 0.681 \\
\hline PAD & 0 & 3 & 0.274 \\
\hline \multicolumn{4}{|l|}{ Cardiac } \\
\hline High risk & 0 & 2 & 0.452 \\
\hline Moderate risk & 3 & 3 & \\
\hline Low risk & 12 & 19 & $\mathrm{n} / \mathrm{a}$ \\
\hline Dialysis & 0 & 0 & \\
\hline \multicolumn{4}{|l|}{ Arterial Closure } \\
\hline Patch & 13 & 18 & \\
\hline Primer & 2 & 6 & 0.99 \\
\hline \multicolumn{4}{|l|}{ Carotid lesion } \\
\hline Ipsilateral & $74.27 \pm 16.46$ & $83.63 \pm 14.01$ & 0.066 \\
\hline Contralateral & $26.67 \pm 19.48$ & $29.96 \pm 12.17$ & 0.642 \\
\hline
\end{tabular}

COPD: chronic obstructive pulmonary disease, PAD: peripheral arterial disease, TIA: transient ischemic attack.

Table 2. Symptom to operation time.

\begin{tabular}{|c|c|c|c|c|}
\hline & & Group I (early) $(\mathrm{n}=15)$ & Group II (late) $(\mathrm{n}=24)$ & $\mathrm{p}$ \\
\hline \multirow[t]{9}{*}{ Symptom } & Dizziness & 6 & 11 & \\
\hline & Left-sided hemiparesis & 1 & 2 & \\
\hline & Right-sided hemiparesis & 0 & 5 & \\
\hline & TIA & 2 & 0 & \\
\hline & Uneventful CVE & 0 & 1 & 0.129 \\
\hline & Syncope & 0 & 1 & \\
\hline & Amaurosis fugax & 0 & 1 & \\
\hline & Numbness in the arm & 2 & 0 & \\
\hline & Major stroke & 4 & 3 & \\
\hline
\end{tabular}

TIA: transient ischemic attack, CVA: cerebrovascular event. 
Table 3. 30 day outcomes.

\begin{tabular}{cccc}
\hline 30-day outcomes & Group I (early) $(\mathrm{n}=15)$ & Group II (late) $(\mathrm{n}=24)$ & $\mathrm{p}$ \\
\hline Mortality & 1 & 0 & 0.2 \\
Stroke & 2 & 0 & 0.066 \\
MI & 0 & 0 & $\mathrm{n} / \mathrm{a}$ \\
Bleeding & 0 & 1 & 0.423 \\
\hline
\end{tabular}

MI: myocardial infarction.

Table 4. Operation years vs groups.

\begin{tabular}{lcccc}
\hline & & Group I (early) $(\mathrm{n}=15)$ & Group II (late) $(\mathrm{n}=24)$ & $\mathrm{p}$ \\
\hline Operation year & 2008 & 0 & 4 & \\
\\
2009 & 1 & 5 & \\
& 2010 & 5 & 5 & 0.196 \\
2011 & 2 & 4 & \\
\hline
\end{tabular}

Bar Chart

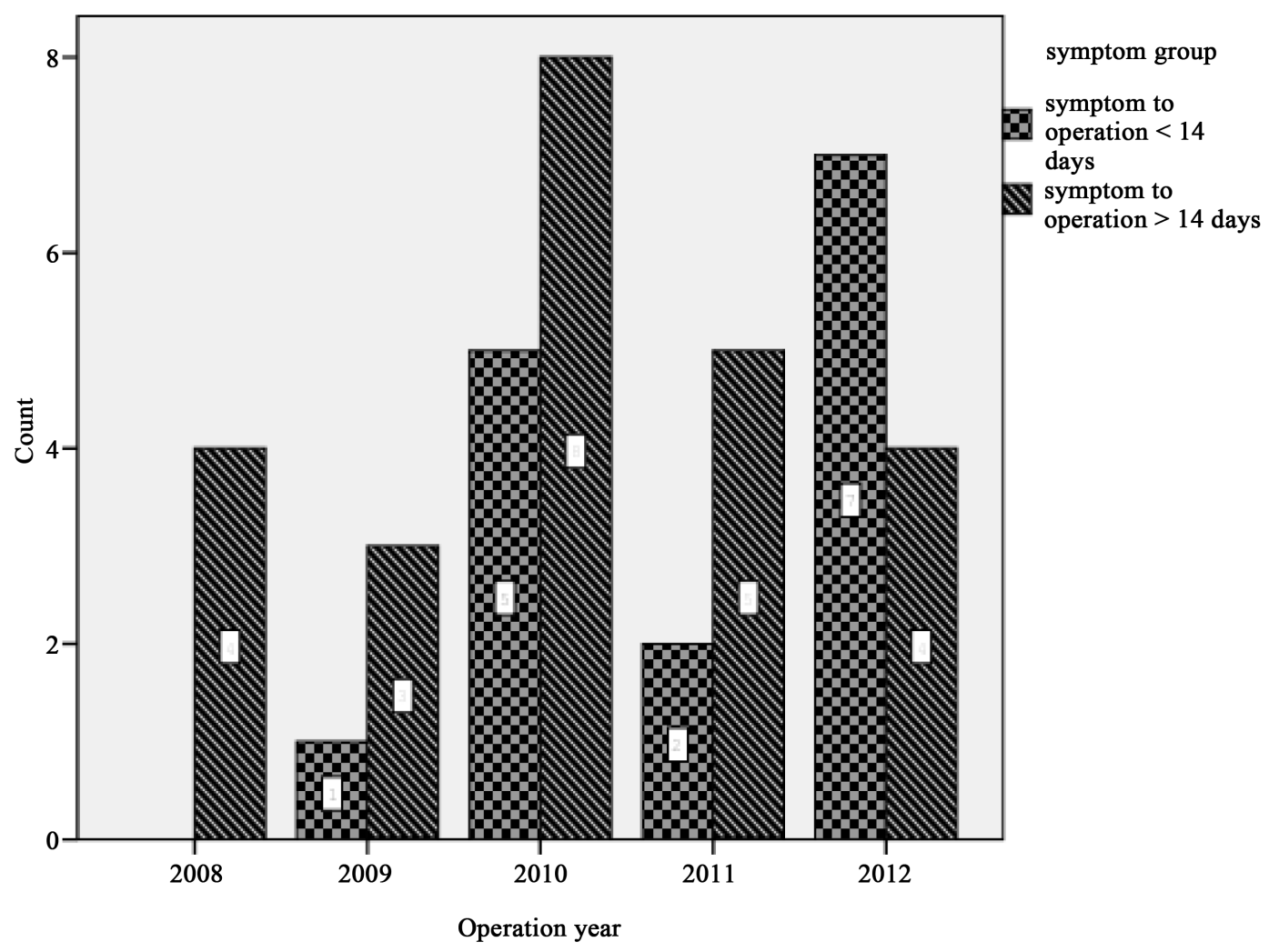

Figure 1. Operation years vs groups.

\section{Discussion}

The main purpose of urgent carotid endarterectomy is to improve blood flow to ischemic areas and eradicate the source of embolic events secondary to unstable atheromatous plaque in the internal carotid artery. Up to date, guidelines suggest early revascularization [4] but previously reported papers advocate late revascularization due 
to risk of non-hemorrhagic infarct transition into a hemorrhagic one and consequent extension of the infarcted area [9]. Parallel to up to date data, our patients had short waiting time for operation but the difference did not reach statistical significance $(p>0.05)$. The early endarterectomy in symptomatic patients began with the improved results of pooled analysis from the ECST and NASCET trials in the 1990s [10]-[12]. Rantner et al. demonstrated no differences in major complication rates in 29 CEAs performed before or 62 CEAs performed after 28 days from symptoms [13]. More importantly, they observed secondary ischemic stroke in $11.8 \%$ of their delayed CEA cohort during the 4-week waiting period. Ballotta et al. showed in a prospective study of 45 patients randomized to early CEA and 41 randomized to delayed CEA that there was no difference in perioperative stroke rates, survival, or stroke in 3 years [14] Capoccia et al. reported that, 93.5\% (58 of 62) of patients undergoing CEA within 2 weeks of symptom onset experienced National Institutes of Health Stroke [15] Scale (NIHSS) score improvement upon treatment. Finally, as in this study, Paty et al. reported no difference in the rates of perioperative stroke resulting in permanent neurologic deficit by time elapsed after symptom onset (Week 1:2/72, 2.8\%; Week 2:2/59, 3.4\%; Week 3:1/29, 3.4\%; Week 4:2/78, 2.6\%) [16]. We observed postoperative stroke in two (5.1\%) patients in early revascularization group. The etiology was transition to hemorrhagic stroke. Annambhotla et al. reported a significantly higher rate (1.6\%) of perioperative stroke in their late CEA group $(n=243)$ [17]. Faggioli et al. reported no statistical difference of perioperative stroke rate according to operation time [18]. Patients with primary closure of arteriotomy in CEA are prone to postoperative stroke. In this study, we detected that, primary closure is a risk factor for postoperative stroke $(\mathrm{p}<0.05)$. Cochrane library reviews compared different patch materials. The differences were very small. Only reported differences were; PTFE patches were superior to collagen-impregnated Dacron grafts in terms of perioperative stroke and restenosis. We observed no statistical significance. Pseudoaneurysms were more common after a vein patch than with a synthetic patch [19]. Also in a study conducting 48,035 patients, Menyhei et al. reported standard endarterectomy without patch had a significantly higher stroke rate than the standard method with patch [20]. Although there are papers saying intracerebral hemorrhage may be main reason for cerebrovascular complications there widely held beliefs to claim microemboli. David G et al. reported intracerebral hemorrhage as cause of post CEA cerebrovascular event [21] Verhoeven suggests that, prevention of embolic events should contribute to a decrease in adverse cerebral events. He believes emboli occurring not only during dissection of the atherosclerotic plaque are associated with an increased risk of surgery and during closure of the vessel are also related with adverse outcome [22]-[24]. None of patients had perioperative myocardial infarction (MI). NASCET trial reported 0.5\% post CEA MI and Bevilacqua and friends reported 1.1\% postoperative MI [10] [25]. We had observed 30 day mortality in 1 (2.5\%) patient which was in Early Group. Our result was parallel to literature [10] [11].

This study had some limitations. Because this study was retrospective and randomization between patch materials was not performed, it is conceivable that there are differences in patient characteristics among the groups and that a selection bias led to the use of patches in patients with more severe disease. However, we studied these characteristics and could not identify such a difference. Additionally, the study was limited by the number of patients with CEA. Finally, our long-term follow-up was limited to 30 days.

\section{Conclusion}

Although symptomatic patients have a higher risk of perioperative complications compared with asymptomatic patients, early CEA after symptom onset does not influence the results. This raises the question of the optimal timing of Carotid Artery intervention in symptomatic carotid artery stenosis. To answer this question, more data are needed, preferably from large randomized trials.

\section{Acknowledgements}

Special thanks to Necla Yildiz and Cemile Cevik for secretarial effort during study time.

\section{Congresses}

None.

\section{Funding}

None. 


\section{Conflicts of Interest}

None.

\section{References}

[1] Diagnostiek, R. (2013) Behandeling en zorg voor patiënten met een beroerte. https://www.nvvc.nl/media/richtlijn/13/Richtlijn\%20Beroerte\%20def-2009.pdf

[2] den Hartog, A.G., Moll, F.L., van der Worp, H.B., Hoff, R.G., Kappelle, L.J. and de Borst, G.J. (2014) Delay to Carotid Endarterectomy in Patients with Symptomatic Carotid Artery Stenosis. European Journal of Vascular and Endovascular Surgery, 47, 233-239.

[3] Brott, T.G., Halperin, J.L., Abbara, S., Bacharach, J.M., Barr, J.D., Bush, R.L., et al. (2011) 2011 ASA/ACCF/AHA/ AANN/AANS/ACR/ASNR/CNS/SAIP/ SCAI/SIR/SNIS/SVM/SVS Guideline on the Management of Patients with Extracranial Carotid and Vertebral Artery Disease: Executive Summary. Circulation, 124, 489-532.

[4] European Stroke Organisation (ESO) Executive Committee, ESO Writing Committee (2008) Guidelines for Management of İschaemic Stroke and Transient İschaemic Attack 2008. Cerebrovascular Diseases, 25, 457-507.

[5] Liapis, C.D., Bell, P.R., Mikhailidis, D., Sivenius, J., Nicolaides, A., Fernandes e Fernandes, J., et al. (2009) ESVS Guidelines. Invasive Treatment for Carotid Stenosis: İndications, Techniques. European Journal of Vascular and Endovascular Surgery, 37, 1-19.

[6] Gladstone, D.J., Oh, J., Fang, J., Lindsay, P., Tu, J.V., Silver, F.L., et al. (2009) Urgency of Carotid Endarterectomy for Secondary Stroke Prevention: Results from the Registry of the Canadian Stroke Network. Stroke, 40, $2776-2782$.

[7] Halliday, A.W., Lees, T., Kamugasha, D., Grant, R., Hoffman, A., Rothwell, P.M., et al. (2009) Waiting Times for Carotid Endarterectomy in UK: Observational Study. BMJ, 338, b1847.

[8] Vikatmaa, P., Sairanen, T., Lindholm, J.M., Capraro, L., Lepantalo, M. and Venermo, M. (2011) Structure of delay in carotid surgery e an observational study. European Journal of Vascular and Endovascular Surgery, 42, 273-279.

[9] Rockman, C.B., Maldonado, T.S., Jacobowitz, G.R., Cayne, N.S., Gagne, P.J. and Riles, T.S. (2006) Early Carotid Endarterectomy in Symptomatic Patients Is Associated with Poorer Perioperative Outcomes. Journal of Vascular Surgery, 44, 480-487. http://dx.doi.org/10.1016/j.jvs.2006.05.022

[10] NASCET Collaborators (1991) Beneficial Effect of Carotid Endarterectomy in Symptomatic Patients with High-Grade Carotid Stenosis. The New England Journal of Medicine, 325, 445-453. http://dx.doi.org/10.1056/NEJM199108153250701

[11] ECST Collaborative Group (1998) Randomised Trial of Endarterectomy for Recently Symptomatic Carotid Stenosis: Final Results of the MRC European Carotid Surgery Trial (ECST). The Lancet, 351, 1379-1387. http://dx.doi.org/10.1016/S0140-6736(97)09292-1

[12] Barnett, H.J., Taylor, D.W., Eliasziw, M., Fox, A.J., Ferguson, G.G., Haynes, R.B., et al. (1998) Benefit of Carotid Endarterectomy in Patients with Symptomatic Moderate or Severe Stenosis. The New England Journal of Medicine, 339, 1415-1425. http://dx.doi.org/10.1056/NEJM199811123392002

[13] Rantner, B., Pavelka, M., Posch, L., Schmidauer, C. and Fraedrich, G. (2005) Carotid Endarterectomy after Ischemic Stroke-Is There a Justification for Delayed Surgery? European Journal of Vascular and Endovascular Surgery, 30, 36-40. http://dx.doi.org/10.1016/j.ejvs.2005.02.045

[14] Ballotta, E., Da Giau, G., Baracchini, C., Abbruzzese, E., Saladini, M. and Meneghetti, G. (2002) Early versus Delayed Carotid Endarterectomy after a Nondisabling Ischemic Stroke: A Prospective Randomized Study. Surgery, 131, 287293. http://dx.doi.org/10.1067/msy.2002.119987

[15] Capoccia, L., Sbarigia, E., Speziale, F., Toni, D. and Fiorani, P. (2011) Urgent Carotid Endarterectomy to Prevent Recurrence and Improve Neurologic Outcome in Mild-to-Moderate Acute Neurologic Events. Journal of Vascular Surgery, 53, 622-628. http://dx.doi.org/10.1016/j.jvs.2010.09.016

[16] Paty, P.S., Darling, R.C., Feustel, P.J., Bernardini, G.L., Mehta, M., Ozsvath, K.J., et al. (2004) Early Carotid Endarterectomy after Acute Stroke. Journal of Vascular Surgery, 39, 148-154. http://dx.doi.org/10.1016/j.jvs.2003.08.003

[17] Annambhotla, S., Park, M.S., Keldahl, M.L., Morasch, M.D., Rodriguez, H.E., Pearce, W.H., Kibbe, M.R. and Eskandari, M.K. (2012) Early versus Delayed Carotid Endarterectomy in Symptomatic Patients. Journal of Vascular Surgery, 56, 1296-1302. http://dx.doi.org/10.1016/j.jvs.2012.05.070

[18] Faggioli, G., Pini, R., Mauro, R., Gargiulo, M., Freyrie, A. and Stella, A. (2013) Perioperative Outcome of Carotid Endarterectomy According to Type and Timing of Neurologic Symptoms and Computed Tomography Findings. Annals of Vascular Surgery, 27, 874-882. http://dx.doi.org/10.1016/j.avsg.2012.12.003

[19] Bond, R., Rerkasem, K., AbuRahma, A.F., Naylor, A.R. and Rothwell, P.M. (2004) Patch Angioplasty versus Primary Closure for Carotid Endarterectomy. (Cochrane Review). The Cochrane Library, 2. Update Software, Oxford. 
[20] Menyhei, G., Björck, M., Beiles, B., Halbakken, E., Jensen, L.P., Lees, T., Palombo, D., et al. (2011) Outcome Following Carotid Endarterectomy: Lessons Learned from a Large International Vascular Registry. European Journal of Vascular and Endovascular Surgery, 41, 735-740. http://dx.doi.org/10.1016/j.ejvs.2011.02.028

[21] Piepgras, D., Morgan, M., Sundt, T.M., Yanagihara, T. and Mussman, L. (1988) Intracerebral Hemorrhage after Carotid Endarterectomy. Journal of Neurosurgery, 68, 532-536. http://dx.doi.org/10.3171/jns.1988.68.4.0532

[22] Ackerstaff, R.G., Moons, K.G., van der Vlasakker, C.J., Moll, F.L., Vermeulen, F.E., Algra, A., et al. (2000) Association of Intraoperative Transcranial Doppler Monitoring Variables with Stroke from Carotid Endarterectomy. European Journal of Vascular and Endovascular Surgery, 19, 226-232.

[23] Laman, D.M., Wieneke, G.H., van Duijn, H. and van Huffelen, A.C. (2002) High Embolic Rate Early after Carotid Endarterectomy Is Associated with Early Cerebrovascular Complications, Especially in Women. Journal of Vascular Surgery, 36, 278-284. http://dx.doi.org/10.1067/mva.2002.125796

[24] Verhoeven, B.A.N., Pasterkamp, G., de Jean-Paul, P.M., Ackerstaff, R.G.A., de Kleijn, D., Eikelboom, B.C. and Moll, F.L. (2005) Closure of the Arteriotomy after Carotid Endarterectomy: Patch Type Is Related to Intraoperative Microemboli and Restenosis Rate. Journal of Vascular Surgery, 42, 1082-1088. http://dx.doi.org/10.1016/j.jvs.2005.08.011

[25] Bevilacqua, S., Romagnoli, S., Ciappi, F., Lazzeri, C., Gelsomino, S., Pratesi, C., et al. (2009) Anesthesia for Carotid Endarterectomy: The Third Option. Patient Cooperation during General Anesthesia. Anesthesia \& Analgesia, 108, 1929-1936. http://dx.doi.org/10.1213/ane.0b013e31819f6f7b 
Scientific Research Publishing (SCIRP) is one of the largest Open Access journal publishers. It is currently publishing more than 200 open access, online, peer-reviewed journals covering a wide range of academic disciplines. SCIRP serves the worldwide academic communities and contributes to the progress and application of science with its publication.

Other selected journals from SCIRP are listed as below. Submit your manuscript to us via either submit@scirp.org or Online Submission Portal.
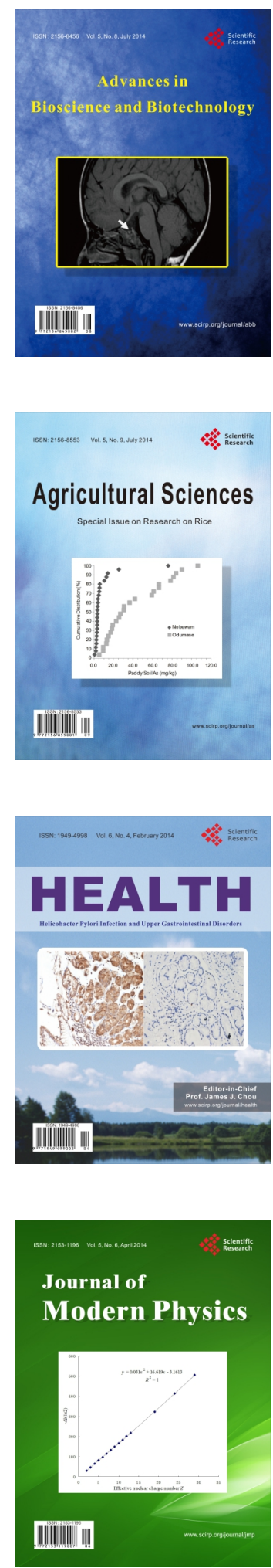
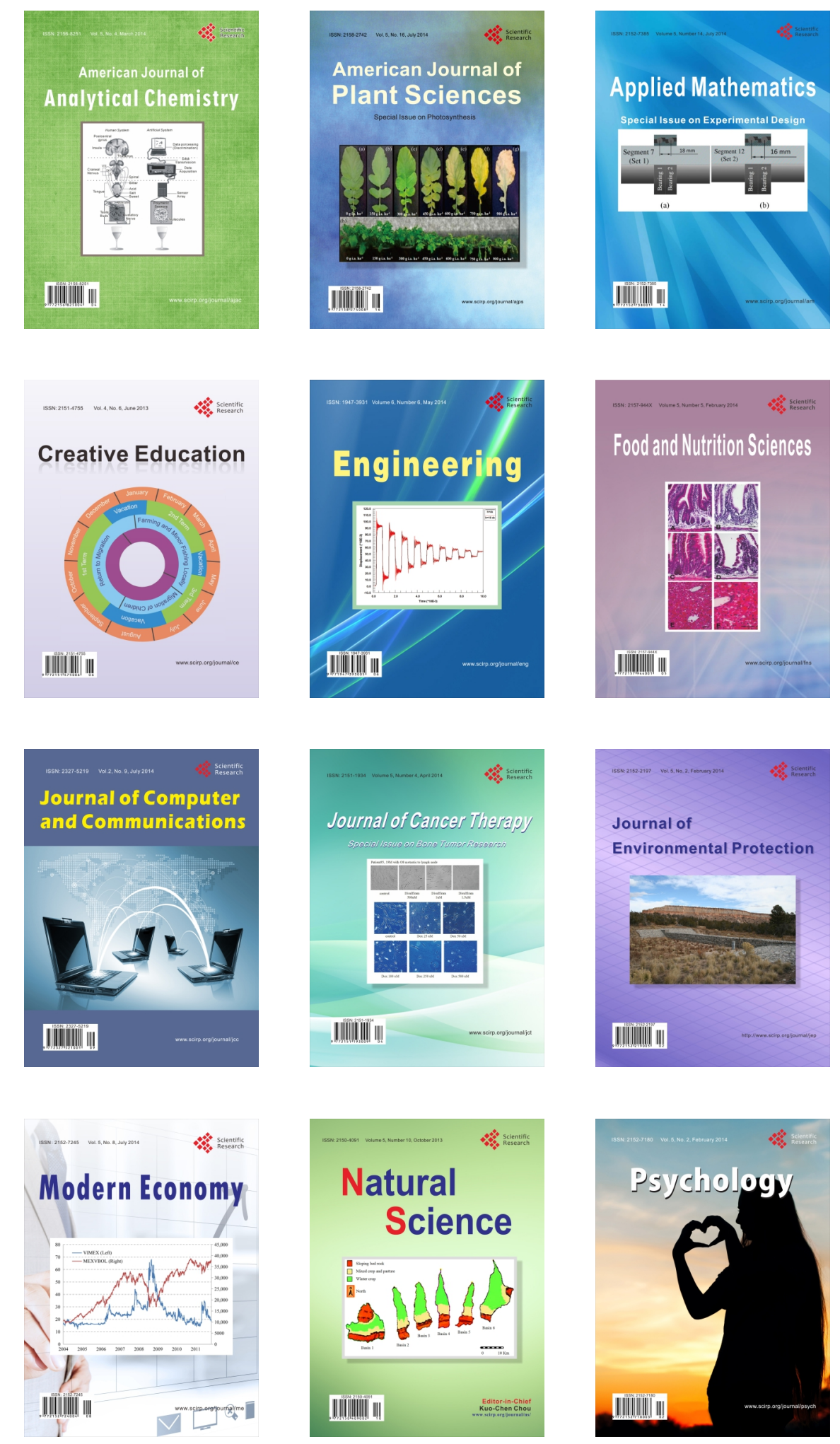